\title{
1 Engineers Seeking Knowledge: The Effect of Control Systems on the \\ 2 Accessibility of Tacit and Codified Knowledge
}

3 Cristina Poleacovschi, PhD, Assistant Professor, Iowa State University, Town Engineering

4 Building, 394 Town Engineering, Ames, IA 50011, poleacov@iastate.edu, Corresponding author

5 Amy Javernick-Will, PhD, Associate Professor, University of Colorado Boulder, UCB 428, ECOT

6 512, Boulder, CO, 80309-0428, amy.javernick@colorado.edu

7 Tony Tong, PhD, Professor, University of Colorado Boulder, 995 Regent Drive, Koelbel 401, 419

8 UCB, Boulder, CO 80309-0419, tony.tong@colorado.edu

9 John Wanberg, PhD, Knowledge Strategy Management, Stantec, 1560 Broadway \#1800, Denver,

10 CO 80202, john.wanberg@stantec.com

12 Abstract

13 Engineering and construction organizations realize that knowledge sharing between

14 employees is essential to be competitive, yet few understand how knowledge sharing is affected

15 by management choices. This paper examines how managerial control systems, the structures and

16 routines used to influence organizational activities, influence knowledge accessibility, defined as

17 the effort that one takes to request and access knowledge from another person. Specifically, this

18 research examines and compares the effects of clan and bureaucratic control on the accessibility

19 of tacit versus codified knowledge. The researchers propose that individuals who perceive greater

20 clan control, or governance through common values and beliefs, will perceive greater accessibility

21 of both tacit and codified knowledge; while individuals who perceive greater bureaucratic control,

22 or governance through rules and procedures, will perceive increase in codified knowledge only. 
23 To test the role of alignment between control systems and knowledge types in affecting knowledge

24 accessibility, a questionnaire was administered to all engineers located in North America (855

25 people) within one engineering organization, and data collected from 298 responses were analyzed

26 using linear regression analysis. The results in this research improve our understanding of

27 knowledge accessibility and is an important step toward integrating control systems, knowledge

28 type and knowledge accessibility.

\section{Introduction}

The Engineering Procurement and Construction (EPC) industry is primarily knowledge-

31 based, which means that the competitive advantage of organizations is significantly determined by

32 how effective organizations are at knowledge sharing. For example, to meet client needs, engineers

33 seek knowledge from each other when they encounter design challenges, take an unfamiliar

34 technical approach, or need someone to collaborate with them to solve a problem (Robinson 2010).

35 However, while practitioners acknowledge the critical nature of knowledge sharing for the success

36 of the organization, it is not readily apparent how organizations can govern knowledge sharing in

37 a way that best benefits project teams. Many organizations have focused on tools and knowledge

38 management systems that attempt to capture knowledge; but many of these systems, lessons

39 learned databases, and skills matrices fail to achieve their intent in practice (Storey and Barnett

40 2000). As a result, additional work is needed to determine how organizations can facilitate

41 knowledge sharing. To address this need, this research analyzes how control systems, the formal

42 and informal structures and routines used to influence organizational activities (Long et al. 2002),

43 affect perceptions of knowledge accessibility, or the effort that one takes to request and access

44 knowledge from another person (Woudstra et al. 2012). Knowledge accessibility is the initial step

45 in knowledge sharing, and is essential in project teams where engineers must access knowledge 
46 quickly from their peers to meet project deadlines (Poleacovschi et al. 2017). Past work has

47 acknowledged the importance of knowledge accessibility by showing that teams and individuals

48 who have higher knowledge accessibility were more likely to have increased project and individual

49 performance (Cross and Cummings 2004; Haas 2006; Poleacovschi and Javernick-Will 2016).

While literature has increased focus on the mechanisms facilitating knowledge sharing and

51 knowledge accessibility (e.g., Hertzum 2014; Javernick-Will 2012; Wanberg et al. 2015), there

52 has been little work that investigates how the control systems initiated by management influence

53 an employee's ability to find and access knowledge needed to complete their projects. Managers

54 within EPC organizations adopt different control systems to influence individual behavior in a way

55 that best aligns with project and organizational goals (Tuuli et al. 2010a). Two forms of control

56 systems - clan and bureaucratic control — have been identified as distinct and critical systems to

57 govern individual behavior (Ouchi 1980). Clan control emphasizes the collective and, as a result,

58 values collaboration to achieve individual goals. In contrast, the management within bureaucratic

59 control systems monitors if employees follow the rules and procedures during their work (Long et

60 al. 2002). Both control systems operate through mechanisms or methods by which individual

61 action is governed (Cardinal et al. 2004). For instance, clan control relies upon common values,

62 traditions and beliefs, while bureaucratic control relies upon rules, standards and formal

63 procedures to complete work (Ouchi 1980). We theorize that control systems will influence

64 knowledge accessibility as they affect individuals' motivation in the process of knowledge

65 seeking. However, the relationship will also depend on the knowledge type. One of the most

66 important differentiating characteristics of knowledge is whether the knowledge is tacit or explicit

67 (Levin and Cross 2004; Nonaka 1994; Polanyi 1967). Tacit knowledge is knowledge that is

68 difficult to articulate in writing and can be explained easier through verbal and social interactions 
69 (Polanyi 1967). Conversely, codified knowledge can be easily written down and does not

70 necessarily require social interactions for transferring (Polanyi 1967). Because knowledge applied

71 in EPC organizations can be both codified and tacit, the overall goal of the research is to contrast

72 the effects of clan and bureaucratic control on the accessibility of tacit and codified knowledge.

73 The research uses survey data and linear regression analysis to test whether clan and

74 bureaucratic control increases accessibility of tacit and codified knowledge. We administered the

75 survey questionnaire to 855 engineers located in North America within one EPC organization, and

76 analyzed responses using linear regression analysis for knowledge accessibility and control

77 systems. Based upon the 298 responses received, we show that increased clan control is positively

78 associated with accessibility of tacit and codified knowledge, while bureaucratic control is

79 positively associated with accessibility of codified knowledge only.

\section{Literature Review}

81 This work falls at the intersection of control systems, knowledge accessibility, and

82 knowledge type, which are reviewed briefly below before developing the hypotheses.

\section{Control Systems}

84 The concept of control systems was proposed by Ouchi (1980) to describe how 85 organizational control mechanisms manage individual behavior. The bureaucratic and clan

86 systems are two distinct and important control mechanisms in EPC organizations (Tuuli et al.

87 2010a; b). Bureaucratic control encourages employees to follow organizational and management

88 procedures to access knowledge from others in the organization. This approach emphasizes

89 structure and rules of the management (Lam 2000; Weber et al. 1958). In bureaucracies, seekers

90 tend to work according to formal organizational charts and procedures. Thus, bureaucratic control

91 emphasizes the importance of documentation, reporting, and standardization as ways of executing 
92 everyday work. In contrast, clans are groups of people who have common understanding, values,

93 and beliefs. In clans, collaboration, reciprocity and common understanding become the norm

94 among team members (Kirsch et al. 2009). Individuals work towards a common goal, which

95 becomes an individual value. A culture of collaborative work de-emphasizes a hierarchy of actors

96 and emphasizes the importance of the parts (people) to the whole (project). In EPC organizations,

97 both control mechanisms are used to influence individual behavior, although managers choose to

98 use bureaucratic control mechanisms more frequently than clan control (Tuuli et al. 2010b; a).

99 Because control systems cannot be disconnected from individual behavior and motivation (Foss et

100 al. 2010; Grandori 1997; Turner and Makhija 2006), the research presented in this paper studies

101 how control systems influence knowledge accessibility.

\section{Knowledge Accessibility}

103 Past research on knowledge accessibility has primarily focused on the antecedents of

104 knowledge accessibility between two individuals. This work has shown that accessibility is

105 influenced by individual attributes (e.g. gender, tenure, hierarchy level) (Borgatti and Cross 2003)

106 and dyadic attributes, or attributes regarding the relationship between the knowledge seeker and

107 knowledge provider (Hertzum 2014; Vancouver and Morrison 1995). For instance, men were

108 likely to perceive decreased knowledge accessibility compared to women (Lee 2000); and

109 relationship quality (Vancouver and Morrison 1995), tie strength (Levin and Cross 2004) and trust

110 (Abrams et al. 2003; Levin and Cross 2004) were found to be important, as people who have close

111 relationships can communicate and access knowledge easily. While individual- and dyad- level

112 attributes are essential, this research addresses another important factor - control systems

113 implemented by management - to determine the influence of managerial control systems on

114 knowledge accessibility among employees. 
116 to define and measure accessibility based upon the social, cognitive and physical effort that people

117 take when seeking for knowledge. Social effort represents the level of psychological comfort that

118 people experience when interacting with the knowledge source. For instance, an engineer may

119 perceive decreased accessibility with a provider because he or she does not want to reveal his/her

120 lack of knowledge to the provider. Cognitive effort refers to the effort that arises based on people

121 who speak different professional languages or who have a different perspective of the project work,

122 requiring additional time to interpret their expertise. Cognitive effort can occur between two

123 engineers who have different technical expertise because they speak different professional

124 language. Physical effort is important for accessibility based upon the potential inconvenience that

125 occurs as a result of accessing knowledge from people who are located in different locations and

126 time zones. For instance, two engineers who work virtually may exert additional effort to

127 communicate compared to two engineers who work in the same office location. The framework is

128 theoretically and analytically suitable for the concept of knowledge accessibility, as it examines

129 the different forces that may influence people's desire to approach other people for knowledge.

\section{$130 \quad$ Knowledge Type}

131 Knowledge type influences the ways employees interact to access and obtain needed

132 knowledge. The most common knowledge type emphasized in the literature is tacit and codified

133 knowledge (Kogut and Zander 1996; Lam 2000; Nonaka and von Krogh 2009; Polanyi 1967; Su

134 and Contractor 2011). Tacit knowledge is knowledge that is contextual, requiring rich descriptions

135 of the problem's context and ease of communication between the knowledge seeker and provider.

136 Tacit knowledge is frequently used within project-based organizations where project members

137 need to share complex knowledge and create innovative solutions to project details. Codified 
138 knowledge is also important in the context of EPC organizations, as quality control processes and

139 checklists are often needed to ensure compliance with professional standards and codes.

140 Because of the importance of the two characteristics of knowledge for everyday 141 construction engineering tasks, previous work identified the antecedents of transferring tacit and 142 codified knowledge (Hansen 1999; Holste and Fields 2010; Levin and Cross 2004). For instance,

143 Hansen (1999) showed that transferring tacit knowledge requires strong ties, or connections that

144 have frequent interactions, while codified knowledge can be transferred using weak ties, or 145 connections that have less frequent interactions. Holste and Fields (2010) have shown that 146 individuals need to build trust in order to easily share tacit knowledge. Nevertheless, these studies

147 have primarily focused on the relational and individual level antecedents of seeking and 148 transferring knowledge, leaving the effect of control systems on knowledge accessibility 149 understudied.

\section{Hypotheses Development}

151 The study of control systems on accessibility is primarily rooted in studies researching the

152 fit between control systems and organizational outcomes. While not directly using the term 153 "accessibility", the accessibility of knowledge is implied in this past work when using the term 154 "fit" and "alignment" (Lam 2000; Osterloh and Frey 2000; Turner and Makhija 2006). For 155 instance, scholars identified the alignment between control systems and the dominant knowledge 156 type (tacit or codified) that described the work conducted by the organization (Lam 2000; Osterloh 157 and Frey 2000; Turner and Makhija 2006). It was theorized that clans would be appropriate for the 158 accessibility of tacit knowledge, while bureaucratic control would be the best fit for the 159 accessibility of codified knowledge (Lam 2000; Osterloh and Frey 2000; Turner and Makhija 160 2006). In other words, if the complexity of a construction project is reduced to more specialized 
161 and repetitive work, or codified knowledge, then the management could adopt a bureaucratic 162 approach with increased rules and procedures. However, this past work did not empirically 163 evaluate the effects of control systems on knowledge accessibility at the dyad level. Bureaucratic control encourages employees to follow organizational and management 165 procedures to access knowledge from others in the organization. Within bureaucracies, individuals 166 may have autonomy, but they have more difficulty transferring tacit knowledge with others due to 167 the increased formality of the working processes (Lam 2000). Specifically, tacit knowledge is more 168 difficult to transfer as it is often context-specific and requires close social relationships and 169 frequent communication with the knowledge provider. For instance, Levin and Cross (2004) have 170 shown that people need to trust the knowledge provider in order to seek knowledge from them. In 171 bureaucracies, seekers tend to work according to formal organizational charts and procedures, 172 which may not facilitate verbal and ad hoc conversations necessary for accessing and transferring 173 tacit knowledge. Thus, bureaucracies advantage formality and create communication channels that

174 allow the easy transfer of knowledge that is written, or codified, such as standards and codes. As 175 such, we expect that knowledge seekers will perceive increased accessibility of codified 176 knowledge.

177 Hypothesis 1: Bureaucratic control will be positively associated with accessibility of codified 178 knowledge but not tacit knowledge.

179 In clans, collaboration becomes the norm among team members who seek to function based 180 on trust and reciprocity (Kirsch et al. 2009). Within clans, individuals will value other employees' 181 expertise and provide their knowledge to whomever needs it, rather than relying on formal 182 hierarchical or social positions. This is expected to increase the accessibility of knowledge. 183 Specifically, we expect tacit knowledge to be accessed easily due to increased social interactions 
184 within clans. Similarly, we expect that the accessibility of codified knowledge will also be

185 increased among clans, as the transfer of codified knowledge requires minimal effort given the

186 well-established communication channels present in clans. As a result, we can expect that in an

187 environment in which clan control is enhanced, knowledge accessibility of both tacit and codified

188 knowledge will increase.

189 Hypothesis 2: Clan control will be positively associated with accessibility of tacit and codified

190 knowledge.

191 Methods

192 The context of this research is one large EPC organization. The organization focuses 193 primarily on providing design and construction services in water and wastewater.

194 Data Collection

195 Initially, a pilot survey was sent to a random sample of 50 employees at the organization

196 to validate the clarity of the survey questions and to check the reliability of the measures for key

197 variables (knowledge accessibility, control systems). Based upon the feedback received, the order

198 of the survey questions was rearranged from two sections into three sections, allowing respondents

199 to reflect between sections. The Cronbach's alpha for the items for measuring variables of

200 knowledge accessibility and control systems was always above 0.7 , which validated the use of the

201 items for the final survey.

202 The final survey was administered to 855 employees in the company who represented the 203 entire group of technical employees (e.g. engineers, architects, scientists) in the North America 204 region. 298 valid responses were returned, representing a survey response rate of $34.8 \%$. In the 205 questionnaire, individuals were asked to identify two people from the organization whom they 206 sought knowledge from (Borgatti and Cross 2003; Cross and Cummings 2004): “During our work, 
we sometimes encounter problems we do not know how to solve and need additional information

208 and advice. Please identify two people at [the company] that you have approached for information

209 or advice to solve a problem." Afterwards, the respondents were asked to evaluate knowledge

210 accessibility, attributes of the knowledge provider and themselves (the knowledge seeker), and to

211 rate the level of clan and bureaucratic control employed by their managers. The unit of analysis of

212 the independent variable represents the respondent's assessment of clan and bureaucratic control,

213 and the unit of analysis of the dependent variable represents the accessibility of the knowledge

214 providers. 41 respondents rated only one provider, but these respondents' answers were included

215 in the empirical analysis for completeness. As a result, the analyses in this paper is based on 555

216 dyads.

217 Variables and Measurement

218 Dependent Variable

219 Our dependent variable is Knowledge accessibility. Woudstra et al. (2012) proposed a 220 three-item framework to measure knowledge accessibility, defined as the effort, including 221 physical, cognitive and social, that one takes to ask and request knowledge from another person. 222 Drawing on Woudstra et al.'s (2012) framework, the following eight items were used to measure 223 accessibility: 1. This person's information and advice is easy to comprehend and use (Anderson 224 et al. 2001); 2. The person's information and advice is easy to understand (Xu et al. 2006); 3. I 225 feel comfortable approaching this person (Morrison and Vancouver 2000); 4. I feel nervous 226 approaching this person (Xu et al. 2006); 5. I do not feel comfortable revealing my lack of 227 knowledge to this person (Fidel and Green 2004); 6. I feel indebted to this person when asking 228 questions from them (Borgatti and Cross 2003); 7. Approaching this person takes significant 229 physical effort (adapted from Woudstra et al., 2012); 8. Approaching this person takes significant 
230 time (adapted from Woudstra et al., 2012). Respondents were asked to assess the eight items based

231 on the following scale (from 1 to 5): "Strongly disagree, Disagree, Neither agree not disagree,

232 Agree, and Strongly agree." The dependent variable, accessibility, was calculated by averaging

233 the eight items. The Cronbach's alpha for the items was 0.78 , which showed the reliability of the

234 items measuring accessibility.

235 Independent Variables

236 The two independent variables related to control systems (Bureaucratic control and Clan

237 control) were measured by following Long et al.'s (2011) approach. To measure the level of

238 bureaucratic control and clan control, respondents were asked to assess five items each using the

239 scale of "Strongly disagree, Disagree, Neither agree not disagree, Agree, and Strongly agree".

240 Specifically, for bureaucratic control, respondents were asked to assess the following five items,

241 where " $\mathrm{X}$ " represents the name of the connection indicated by the respondent: (1) X (supervisor)

242 primarily monitors how well I execute standardized rules and procedures when I do my work; (2)

$243 X$ (supervisor) emphasizes the need for employees to follow rules and procedures in doing their

244 job; (3) X (supervisor) rewards employees who accurately follow rules and procedures in doing

245 their jobs. (4) Whether I succeed or not in this organization is largely determined by how well I

246 execute formal rules and procedures; (5) In doing my job, I spend most of my time executing rules

247 and procedures. For clan control, respondents were asked to assess the following five items: (1) $X$

248 (supervisor) primarily monitors how well I get along with my co-workers; (2) X (supervisor)

249 emphasizes the need for employees to get along with each other; (3) X (supervisor) rewards

250 employees who get along well with their co-workers. (4) Whether I succeed or not in this

251 organization is largely determined by how well I get along with my co-workers. (5) In doing my

252 job, I spend most of my time collaborating with colleagues on work activities. Given that all items 
253 were theorized to have equal weight in measuring control systems (Long et al. 2011), the two

254 independent variables, Bureaucratic control and Clan control, were calculated as an average of

255 the first set of five items, and the second set of five items, respectively.

256 Another independent variable, Knowledge tacitness, was measured by using three items

257 from Hansen (1999): (1) How much of the information/advice that came from X was explained to

258 you in writing (in written reports, manuals, e-mails, faxes, etc.) [None, Almost none, Less than

259 half, Half, More than half, Almost all, All]; (2) How well documented in writing, was the

260 information/advice that you received from X? Consider all the information or advice. [Not well

261 documented, Less documented, Somewhat less documented, Somewhat well documented,

262 Documented, Well documented, Very well documented]; (3) What type of information/advice came

263 from X? [7=mainly reports, manuals, documents; 4=half knowledge explained verbally, half

264 reports/documents; $1=$ mainly personal practical knowledge explained verbally]. The variable

265 Knowledge tacitness was calculated by averaging the three items.

266 Control Variables

267 Based on previous literature, the following variables were controlled for that may affect 268 knowledge accessibility:

269 - Similar age (Sim_age): Respondents were asked to indicate their age in number of years.

270 They were also asked if they were in the same age group as the knowledge provider (plus

271 or minus 5 years). The variable was treated as dichotomous. It was coded as " 1 " while

272 difference of age was coded as " 0 ". This control variable was included since people of

273 similar age may have similar ways of sharing knowledge (Sanaei et al. 2013).

274 - Similar race (Sim_race): Respondents were asked to identify their race (Hispanic or Latino, 275 Black or African-American, White, Asian Pacific Islander, or Other) and if they were of 
the same race as the knowledge provider. The variable was treated as dichotomous. It was coded as "1" while difference of race was coded as "0". This control variable was included because previous work has shown that similarity of race is essential to how people form friendship relationships that may affect knowledge sharing (Mollica et al. 2003).

- Similar expertise (Sim_expertise): The primary area of expertise for the knowledge seeker and provider was obtained from the database provided by the focal organization. The database included areas of expertise in civil engineering, mechanical engineering, electrical engineering, process engineering, environmental engineering, structural engineering, architecture and construction. The variable was treated as dichotomous. It was coded as "1" while difference in expertise was coded as "0". This control variable was included because people with similar expertise have a good mutual understanding of their expertise, facilitating their knowledge seeking (Borgatti and Cross 2003).

- Similar hierarchy level (Sim_level): A provider's hierarchical level was obtained by asking respondents to specify the provider's level in the hierarchy, in relation to the provider ("He/she is the same hierarchy level; He/she is higher hierarchy level; He/she is in lower hierarchy level; or We do not work together"). The variable was treated as dichotomous. It was coded as "1" while difference in level was coded as " 0 ". This control variable was included because people seeking knowledge from providers in higher levels may not want to reveal their lack of knowledge to them.

- Similarity of office location (Sim_location). Respondents were asked if they worked in the same office location as the provider. The variable was treated as dichotomous. It was coded as " 1 " while difference in location was coded as "0". This control variable was included 
because people in the same location are likely to share and transfer knowledge more frequently (Wanberg et al. 2015).

- Gender (Seeker_gender) and similarity of gender (Sim_gender). Previous work (Poleacovschi et al. 2017) showed that the knowledge seeker's gender (Lee 2002) and similarity in gender between the seeker and provider play an important role in knowledge seeking.

- Tie strength (Tie_strength): Respondents were asked to assess the frequency of interactions with providers using the following scale: "Once every 3 months - Once every 2 months Once a month - Twice a month - Once a week - Twice a week - Once a day". The measure for tie strength was taken from previous research (Hansen 1999; Levin and Cross 2004). The variable was coded on a continuous scale from 1 to 7 . This control variable was included as past work has shown that knowledge accessibility increases with the frequency of communication (Hertzum 2014).

\section{Statistical Approach}

312 Data were analyzed using linear regression analysis. To test the hypotheses on the effects

313 of Bureaucratic control (H1) and Clan control (H2) on the accessibility of codified and tacit

314 knowledge, respectively, the coefficient estimates of the two independent variables and their

315 significance levels were examined by performing subsample analysis, with the split of the full 316 sample at the mean value of Knowledge tacitness. This created a "Codified Knowledge

317 Subsample" where observations have a below-the-mean value of knowledge tacitness, as well as 318 a "Tacit Knowledge Subsample" where observations have an above-the-mean value of knowledge

319 tacitness. Subsample analysis is widely used for comparing coefficients between groups due to the 320 many advantages it offers (Greene 2008): subsample analysis does not require that unexplained 
321 variances be identical between the two groups of firms, and it allows the effects of the right-hand-

322 side covariates to differ between the groups, leading to consistent within-group estimates (Hoetker

323 2007).

324 In addition to comparing the signs and significance levels of the estimated coefficients on

325 Bureaucratic control and Clan control across the subsamples, another analysis was performed to

326 test the two hypotheses formally. Specifically, using the full sample (all observations), an

327 interaction term was created between an independent variable (Bureaucratic control or Clan

328 control) and a dummy variable (Tacit subsample) indicating whether a focal observation was in

329 the Tacit Knowledge Subsample (taking the value 1) or the Codified Knowledge Subsample

330 (taking the value 0). Regressions were run, and the sign and significance level of the estimated

331 coefficient on the interaction term was examined (Bureaucratic control * Tacit sample, or Clan

332 control * Tacit sample). This approach provides a more formal test of whether the estimated

333 coefficient on Bureaucratic control (or Clan control) is significantly different between the two

334 subsamples.

\section{Results}

336 Table 1 reports descriptive statistics for the variables.

Table 1: Descriptive Statistics

\begin{tabular}{lccccc}
\hline & $\begin{array}{c}\text { Number of } \\
\text { Observations }\end{array}$ & Mean & $\begin{array}{c}\text { Standard } \\
\text { deviation }\end{array}$ & Min. & Max. \\
\hline Accessibility & 555 & 4.3 & 0.56 & 1.25 & 5.12 \\
\hline Sim_race & 555 & 1.70 & 0.47 & 1 & 3 \\
Sim_age & 555 & 1.38 & 0.51 & 1 & 3 \\
Sim_gender & 555 & 1.63 & 0.49 & 1 & 3 \\
Sim_location & 555 & 1.59 & 0.53 & 1 & 3 \\
Sim_level & 555 & 1.13 & 0.34 & 1 & 2 \\
Tie_strength & 555 & 5.17 & 1.74 & 1 & 7 \\
Seeker_gender & 555 & 1.63 & 0.48 & 1 & 2 \\
Bureaucratic control & 555 & 3.23 & 0.69 & 1 & 5
\end{tabular}


Clan control

Knowledge tacitness

Tacit subsample
555

555

555
3.30

4.60

0.53
0.57

1.21

0.50

Table 2 presents hypotheses testing results. Models 1-3 report results testing Hypothesis 1,

340 and Models 4-6 report results testing Hypothesis 2. Specifically, Models 1 and 4 are the Codified

341 Knowledge Subsample, Models 2 and 5 are the Tacit Knowledge Subsample, and Models 3 and 6

342 are the Full Sample with all observations.

343

344
Table 2: Results for the Effects of Bureaucratic and Clan Control on the Accessibility of Codified and Tacit Knowledge

\begin{tabular}{|c|c|c|c|c|c|c|}
\hline & $\begin{array}{c}\text { (1) } \\
\text { Codified } \\
\text { Knowledge } \\
\text { Subsample } \\
\end{array}$ & $\begin{array}{c}(2) \\
\text { Tacit } \\
\text { Knowledge } \\
\text { Subsample } \\
\end{array}$ & $\begin{array}{c}\text { (3) } \\
\text { Full } \\
\text { Sample }\end{array}$ & $\begin{array}{c}(4) \\
\text { Codified } \\
\text { Knowledge } \\
\text { Subsample } \\
\end{array}$ & $\begin{array}{c}\text { (5) } \\
\text { Tacit } \\
\text { Knowledge } \\
\text { Subsample }\end{array}$ & $\begin{array}{c}\text { (6) } \\
\text { Full } \\
\text { Sample }\end{array}$ \\
\hline Sim_race & $\begin{array}{l}-0.052 \\
(0.070)\end{array}$ & $\begin{array}{l}-0.043 \\
(0.074)\end{array}$ & $\begin{array}{l}-0.040 \\
(0.050)\end{array}$ & $\begin{array}{l}-0.030 \\
(0.070)\end{array}$ & $\begin{array}{l}-0.020 \\
(0.074)\end{array}$ & $\begin{array}{l}-0.017 \\
(0.051)\end{array}$ \\
\hline Sim_age & $\begin{array}{c}0.068 \\
(0.064)\end{array}$ & $\begin{array}{c}0.177^{*} \\
(0.073)\end{array}$ & $\begin{array}{c}0.115^{*} \\
(0.048)\end{array}$ & $\begin{array}{c}0.043 \\
(0.063)\end{array}$ & $\begin{array}{c}0.175^{*} \\
(0.072)\end{array}$ & $\begin{array}{c}0.103^{*} \\
(0.047)\end{array}$ \\
\hline Sim_gender & $\begin{array}{c}0.116 \\
(0.077)\end{array}$ & $\begin{array}{c}0.144 \\
(0.092)\end{array}$ & $\begin{array}{c}0.120^{*} \\
(0.059)\end{array}$ & $\begin{array}{c}0.109 \\
(0.076)\end{array}$ & $\begin{array}{c}0.142 \\
(0.091)\end{array}$ & $\begin{array}{c}0.116^{*} \\
(0.058)\end{array}$ \\
\hline Sim_location & $\begin{array}{l}-0.060 \\
(0.073)\end{array}$ & $\begin{array}{l}-0.080 \\
(0.074)\end{array}$ & $\begin{array}{l}-0.072 \\
(0.052)\end{array}$ & $\begin{array}{l}-0.043 \\
(0.072)\end{array}$ & $\begin{array}{l}-0.098 \\
(0.074)\end{array}$ & $\begin{array}{l}-0.072 \\
(0.052)\end{array}$ \\
\hline Sim_level & $\begin{array}{l}-0.007 \\
(0.107)\end{array}$ & $\begin{array}{c}0.109 \\
(0.098)\end{array}$ & $\begin{array}{c}0.071 \\
(0.072)\end{array}$ & $\begin{array}{l}-0.029 \\
(0.106)\end{array}$ & $\begin{array}{c}0.142 \\
(0.098)\end{array}$ & $\begin{array}{c}0.081 \\
(0.072)\end{array}$ \\
\hline Tie_strength & $\begin{array}{c}0.035 \\
(0.022)\end{array}$ & $\begin{array}{c}0.070^{* *} \\
(0.023)\end{array}$ & $\begin{array}{c}0.051^{* *} \\
(0.016)\end{array}$ & $\begin{array}{c}0.041 \\
(0.022)\end{array}$ & $\begin{array}{l}0.074^{* *} \\
(0.023)\end{array}$ & $\begin{array}{c}0.056^{* * *} \\
(0.016)\end{array}$ \\
\hline Seeker_gender & $\begin{array}{l}-0.131 \\
(0.079)\end{array}$ & $\begin{array}{l}-0.233^{*} \\
(0.092)\end{array}$ & $\begin{array}{l}-0.179^{* *} \\
(0.059)\end{array}$ & $\begin{array}{l}-0.122 \\
(0.078)\end{array}$ & $\begin{array}{l}-0.233^{4} \\
(0.091)\end{array}$ & $\begin{array}{l}-0.175^{* *} \\
(0.059)\end{array}$ \\
\hline Bureaucratic control & $\begin{array}{c}0.109^{*} \\
(0.052)\end{array}$ & $\begin{array}{l}-0.0001 \\
(0.049)\end{array}$ & $\begin{array}{c}0.115^{*} \\
(0.052)\end{array}$ & & & \\
\hline Tacit subsample & & & $\begin{array}{c}0.398^{\dagger} \\
(0.230)\end{array}$ & & & $\begin{array}{c}0.186 \\
(0.278)\end{array}$ \\
\hline $\begin{array}{l}\text { Bureaucratic control } \\
* \text { Tacit subsample }\end{array}$ & & & $\begin{array}{l}-0.119^{\dagger} \\
(0.069)\end{array}$ & & & \\
\hline
\end{tabular}




\begin{tabular}{|c|c|c|c|c|c|c|}
\hline Clan control & & & & $\begin{array}{c}0.169^{* *} \\
(0.060)\end{array}$ & $\begin{array}{c}0.130^{*} \\
(0.059)\end{array}$ & $\begin{array}{c}0.168^{* *} \\
(0.061)\end{array}$ \\
\hline $\begin{array}{l}\text { Clan control } \\
* \text { Tacit subsample }\end{array}$ & & & & & & $\begin{array}{l}-0.051 \\
(0.083)\end{array}$ \\
\hline Constant & $\begin{array}{l}3.876^{* * *} \\
(0.293)\end{array}$ & $\begin{array}{l}3.956^{* * *} \\
(0.287)\end{array}$ & $\begin{array}{l}3.707^{* * *} \\
(0.239)\end{array}$ & $\begin{array}{l}3.630^{* * *} \\
(0.318)\end{array}$ & $\begin{array}{l}3.448^{* * *} \\
(0.329)\end{array}$ & $\begin{array}{l}3.461^{* * *} \\
(0.270)\end{array}$ \\
\hline$N$ & 260 & 295 & 555 & 260 & 295 & 555 \\
\hline$R^{2}$ & 0.049 & 0.077 & 0.058 & 0.062 & 0.093 & 0.070 \\
\hline$F$ value & 1.619 & 3.025 & 3.363 & 2.086 & 3.716 & 4.126 \\
\hline
\end{tabular}

In Model 1, the coefficient on the variable Bureaucratic control is positive and significant $347(p<0.05)$, suggesting that bureaucratic control is associated with increased accessibility of codified

348 knowledge. In Model 2, the coefficient on Bureaucratic control is not significant, thus bureaucratic 349 control is not associated with accessibility of tacit knowledge. Taken together, results in Models 1

350 and 2 provide support for our H1 that bureaucratic control will be positively related to the 351 accessibility of codified knowledge but not that of tacit knowledge. In Model 3, the coefficient on 352 the interaction term Bureaucratic control * Tacit subsample is negative and modestly significant $353(p<0.10)$, suggesting that the effect of bureaucratic control on tacit knowledge is significantly 354 different (lower) than its effect on codified knowledge. This result also validates the significantly 355 positive coefficient on Bureaucratic control in Model 1 (codified knowledge) but the insignificant 356 coefficient in Model 2 (tacit knowledge). Overall, results in Model 3 provide further support for $357 \quad \mathrm{H} 1$.

358 In Model 4, the coefficient on the variable Clan control is positive and significant $(\mathrm{p}<0.01)$, 359 suggesting that clan control is associated with increased accessibility of codified knowledge. In 360 Model 5, the coefficient on the variable Clan control is similarly positive and significant $(\mathrm{p}<0.05)$, 361 thus clan control is also associated with increased accessibility of tacit knowledge. Taken together, 362 results in Models 4 and 5 provide support for our $\mathrm{H} 2$ that clan control will be positively related to 
363 the accessibility of both codified and tacit knowledge. In Model 6, the coefficient on the interaction

364 term Clan control * Tacit subsample is not significant, suggesting that the effect of clan control

365 on tacit knowledge is not significantly different than its effect on codified knowledge. This result

366 is consistent with the finding earlier that the coefficient on Clan control is positively significant in

367 both Model 4 (codified knowledge) and Model 5 (tacit knowledge), and that the size of the

368 coefficient estimates (and standard errors) for Clan control in both models is relatively close to

369 each other. Overall, results in Model 6 provide further support for $\mathrm{H} 2$.

\section{Discussion}

371 This research sought to understand the influence of control systems (clan and bureaucratic

372 control) on knowledge accessibility based on knowledge types. The results showed that the effect

373 of clan control on accessibility was positive and significant for both tacit and codified knowledge.

374 This means that whenever respondents perceived clan control, they were likely to experience less

375 social, cognitive, and physical effort in accessing knowledge providers regardless of the type of

376 knowledge to seek. In contrast, bureaucratic control had a positive effect on the accessibility of

377 codified knowledge only, meaning that bureaucratic control is not systematically related to the

378 accessibility of tacit knowledge. While control systems have been shown to influence individual

379 behavior, existing literature has not yet studied the link between control systems and knowledge

380 sharing. This study is an important step toward integrating control systems, knowledge type and

381 knowledge accessibility at the dyad level. This research showed that, after controlling for relational

382 attributes (e.g. similarity of gender), the control mechanisms applied by management played an

383 important role on the accessibility of both tacit and codified knowledge. Specifically, people

384 perceived knowledge to be more accessible, regardless of knowledge type, whenever they

385 perceived a clan environment. The results contribute to literature on knowledge sharing and control 
systems by analyzing the effect of two control systems and on the accessibility of tacit and codified

387 knowledge. As such, this research emphasizes the knowledge context as an important variable in

388 the relationship between control systems and knowledge accessibility (Agarwal et al. 2011;

389 Hertzum 2014). While existing work in construction and engineering has primarily focused on the

390 social relations and individual motivation as essential for knowledge sharing (Javernick-Will 2012;

391 Poleacovschi and Javernick-Will 2017; Sanaei et al. 2013), the findings from this research show

392 the importance of control effects on knowledge sharing, and emphasize inclusion of control

393 systems as an important variable in knowledge sharing behavior.

For practitioners, the link between control systems and knowledge accessibility presents

395 important managerial implications. Decisions of control systems should include thought regarding

396 the types of knowledge that employees need to access to complete their work. If their tasks are

397 complex and require them to access tacit knowledge, then clans would be more suited to enhance

398 knowledge accessibility. If the task can be completed based upon existing, codified knowledge

399 within the firm, then either clans or bureaucracies can be implemented. Nevertheless, project

400 managers should consider the costs of fostering bureaucratic and clan control. Employing clan

401 control is expected to be more expensive and time consuming due to socialization among clan

402 members and emotional labor to foster a clan identity. The costs should be especially considered

403 and compared in the case of codified knowledge which can be transferred using both control

404 systems.

\section{Limitations and Future Work}

As with any research, this research contains limitations. First, the assessment of control 407 systems represents the perceptions of the respondents. Future work can evaluate ways to measure 408 control systems using a more objective scale. Alternatively, the assessment of control systems can 
409 be validated through an inter-rater reliability rating, where several employees who have the same

410 supervisors assess the control systems in the survey. Second, clan and bureaucratic control were

411 included, but not market-based control, because monetary compensation has minimal influence on

412 how people share and transfer knowledge (Javernick-Will 2012), and there is a lack of

413 organizations that employ market-based control mechanisms. This work is based on the US market

414 so that cultural differences in knowledge accessibility and control systems could be controlled for,

415 which limits the generalizability of the findings.

\section{Conclusion}

417 In knowledge-based EPC organizations, knowledge accessibility is critical for employees

418 to complete their work effectively. While advances have been made in better understanding how

419 individual and dyadic attributes between a knowledge seeker and provider influence knowledge

420 accessibility, there has been a dearth of research that investigates how managerial control

421 mechanisms influence knowledge sharing and accessibility. Thus, the goal of this research was to

422 determine how different control systems-bureaucratic and clan-influenced knowledge

423 accessibility based on knowledge type. To achieve this goal, a survey was administered to 855

424 technical specialists (i.e., engineers, architects and scientists) within North American offices in an

425 engineering organization and linear regression analysis was used to validate the hypothesis that

426 clan control, or developing an environment supportive of collaboration, positively affected

427 accessibility of both tacit and codified knowledge. In contrast, bureaucratic control affected the

428 accessibility of codified knowledge only. Theoretically, this research improves understanding of

429 knowledge accessibility by showing the link between the control systems and knowledge

430 accessibility, and by specifying that the type of knowledge is important factor in this relationship.

431 Practically, project managers who want to increase accessibility among employees may foster one 
432 of the control systems based on the nature of the project work. If the work requires frequent access

433 to tacit knowledge, then they should consider governing through clan control.

\section{Acknowledgment}

This material is based in part on work supported by a National Science Foundation grant,

material are those of the authors and do not necessarily reflect the views of the National Science

Foundation.

\section{References}

Abrams, L. C., Cross, R., Lesser, E., and Levin, D. Z. (2003). "Nurturing interpersonal trust in knowledge-sharing networks." The Academy of Management Executive, 17(4), 64-77.

Agarwal, N. K., Xu, Y. (Calvin), and Poo, D. C. C. (2011). "A context-based investigation into source use by information seekers." Journal of the American Society for Information Science and Technology, 62(6), 1087-1104.

Anderson, C. J., Glassman, M., McAfee, R. B., and Pinelli, T. (2001). "An investigation of factors affecting how engineers and scientists seek information." Journal of Engineering and Technology Management, 18(2), 131-155.

Borgatti, S. P., and Cross, R. (2003). "A Relational View of Information Seeking and Learning in Social Networks." Management Science, 49(4), 432-445.

Cardinal, L. B., Sitkin, S. B., and Long, C. P. (2004). "Balancing and Rebalancing in the Creation and Evolution of Organizational Control." Organization Science, 15(4), 411431.

Cross, R., and Cummings, J. N. (2004). "Tie and Network Correlates of Individual Performance in Knowledge-Intensive Work." The Academy of Management Journal, 47(6), 928-937.

Fidel, R., and Green, M. (2004). "The Many Faces of Accessibility: Engineers' Perception of Information Sources." Inf. Process. Manage., 40(3), 563-581.

Foss, N. J., Husted, K., and Michailova, S. (2010). "Governing Knowledge Sharing in Organizations: Levels of Analysis, Governance Mechanisms, and Research Directions." Journal of Management Studies, 47(3), 455-482.

Greene, W. (2008). Econometric Analysis. Pearson/Prentice Hall: Upper Saddle River.

Haas, M. R. (2006). "Acquiring and Applying Knowledge in Transnational Teams: The Roles of Cosmopolitans and Locals." Organization Science, 17(3), 367-384.

Hansen, M. T. (1999). "The Search-Transfer Problem: The Role of Weak Ties in Sharing Knowledge across Organization Subunits.” Administrative Science Quarterly, 44(1), 82111.

Hertzum, M. (2014). "Expertise seeking: A review." Information Processing \& Management, $50(5), 775-795$. 
Hoetker, G. (2007). "The use of logit and probit models in strategic management research: Critical issues." Strategic Management Journal, 28(4), 331-343.

Holste, J. S., and Fields, D. (2010). "Trust and tacit knowledge sharing and use." Journal of Knowledge Management, 14(1), 128-140.

Javernick-Will, A. (2012). "Motivating Knowledge Sharing in Engineering and Construction Organizations: Power of Social Motivations.” Journal of Management in Engineering, 28(2), 193-202.

Kirsch, L. J., Ko, D.-G., and Haney, M. H. (2009). "Investigating the Antecedents of TeamBased Clan Control: Adding Social Capital as a Predictor." Organization Science, 21(2), 469-489.

Kogut, B., and Zander, U. (1996). "What Firms Do? Coordination, Identity, and Learning." Organization Science, 7(5), 502-518.

Lam, A. (2000). "Tacit Knowledge, Organizational Learning and Societal Institutions: An Integrated Framework." Organization Studies, 21(3), 487-513.

Lee, F. (2002). "The Social Costs of Seeking Help." The Journal of Applied Behavioral Science, $38(1), 17-35$.

Levin, D. Z., and Cross, R. (2004). "The Strength of Weak Ties You Can Trust: The Mediating Role of Trust in Effective Knowledge Transfer." Management Science, 50(11), 14771490.

Long, C. P., Bendersky, C., and Morrill, C. (2011). "Fairness Monitoring: Linking Managerial Controls and Fairness Judgments in Organizations." Academy of Management Journal, 54(5), 1045-1068.

Long, C. P., Burton, R. M., and Cardinal, L. B. (2002). "Three Controls are Better than One: A Computational Model of Complex Control Systems." Computational \& Mathematical Organization Theory, 8(3), 197-220.

Mollica, K. A., Gray, B., and Treviño, L. K. (2003). "Racial Homophily and Its Persistence in Newcomers' Social Networks.” Organization Science, 14(2), 123-136.

Morrison, E. W., and Vancouver, J. B. (2000). "Within-Person Analysis of Information Seeking: The Effects of Perceived Costs and Benefits." Journal of Management, 26(1), 119-137.

Nickerson, J. A., and Zenger, T. R. (2004). "A Knowledge-Based Theory of the Firm: The Problem-Solving Perspective." Organization Science, 15(6), 617-632.

Nonaka, I. (1994). "A Dynamic Theory of Organizational Knowledge Creation.” Organization Science, 5(1), 14-37.

Nonaka, I., and von Krogh, G. (2009). "Perspective-Tacit Knowledge and Knowledge Conversion: Controversy and Advancement in Organizational Knowledge Creation Theory." Organization Science, 20(3), 635-652.

Osterloh, M., and Frey, B. S. (2000). "Motivation, Knowledge Transfer, and Organizational Forms." Organization Science, 11(5), 538-550.

Ouchi, W. G. (1980). "Markets, Bureaucracies, and Clans.” Administrative Science Quarterly, 25(1), 129-141.

Polanyi, M. (1967). The Tacit Dimension. London, Routledge \& K. Paul.

Poleacovschi, C., and Javernick-Will, A. (2016). "Spanning information and knowledge across subrgoups and its effects on individual performance." Journal of Management in Engineering. 
Poleacovschi, C., and Javernick-Will, A. (2017). "Who Are the Experts? Assessing Expertise in Construction and Engineering Organizations." Journal of Construction Engineering and Management, 143(8), 04017033.

Robinson, M. A. (2010). "An empirical analysis of engineers' information behaviors." Journal of the American Society for Information Science and Technology, 61(4), 640-658.

Sanaei, M., Javernick-Will, A. N., and Chinowsky, P. (2013). "The influence of generation on knowledge sharing connections and methods in construction and engineering organizations headquartered in the US." Construction Management and Economics, 31(9), 991-1004.

Storey, J., and Barnett, E. (2000). "Knowledge management initiatives: learning from failure." Journal of Knowledge Management, 4(2), 145-156.

$\mathrm{Su}, \mathrm{C}$., and Contractor, N. (2011). "A multidimensional network approach to studying team members' information seeking from human and digital knowledge sources in consulting firms." Journal of the American Society for Information Science and Technology, 62(7), $1257-1275$.

Turner, K. L., and Makhija, M. V. (2006). "The Role of Organizational Controls in Managing Knowledge." The Academy of Management Review, 31(1), 197-217.

Tuuli, M. M., Rowlinson, S., and Koh, T. Y. (2010a). "Dynamics of control in construction project teams." Construction Management and Economics, 28(2), 189-202.

Tuuli, M. M., Rowlinson, S., and Koh, T. Y. (2010b). "Dynamics of control in construction project teams." Construction Management and Economics, 28(2), 189-202.

Vancouver, J. B., and Morrison, E. W. (1995). "Feedback Inquiry: The Effect of Source Attributes and Individual Differences." Organizational Behavior and Human Decision Processes, 62(3), 276-285.

Wanberg, J., Javernick-Will, A., Taylor, J. E., and Chinowsky, P. (2015). "The effects of organizational divisions on knowledge-sharing networks in multi-lateral communities of practice." Engineering Project Organization Journal, 5(2-3), 118-132.

Weber, M., Gerth, H., and Mills, C. W. (1958). From Max Weber: essays in sociology. Oxford University Press, New York.

Woudstra, L., van den Hooff, B., and Schouten, A. P. (2012). "Dimensions of quality and accessibility: Selection of human information sources from a social capital perspective." Information Processing \& Management, 48(4), 618-630.

Xu, Y. (Calvin), Tan, B. C. Y., and Yang, L. (2006). "Who will you ask? An empirical study of interpersonal task information seeking." Journal of the American Society for Information Science and Technology, 57(12), 1666-1677. 